\title{
PSYCHOLOGICAL DISTRESS, RELATIONSHIP QUALITY AND WELL-BEING IN TIME OF COVID-19 PANDEMIC MOVEMENT CONTROL ORDER ENACTMENT AMONG COUPLES IN MALAYSIA
}

\author{
Chua Bee Seok ${ }^{1}$, Ching Sin Siau ${ }^{2}$, Low Wah Yun ${ }^{3}$, Mimi Fitriana ${ }^{4}$, \& Rahmattullah Khan ${ }^{5}$ \\ ${ }^{1}$ Faculty of Psychology and Education, University Malaysia Sabah (Malaysia) \\ ${ }^{2}$ Faculty of Health Sciences, Center for Community Health Studies, \\ University Kebangsaan Malaysia (Malaysia) \\ ${ }^{3}$ Asia Europe Institute, Universiti Malaya (Malaysia) \\ ${ }^{4}$ Faculty of Arts and Science, School of Science and Psychology, \\ International University of Malaya-Wales Kuala Lumpur (Malaysia) \\ ${ }^{5}$ University Pendidikan Sultan Idris (Malaysia)
}

\begin{abstract}
With the imposition of the Movement Control Order (MCO) or lockdown due to the COVID-19 pandemic, there are drastic changes in the movement and activity among Malaysians: increased psychological distress due to perception of the COVID-19 as a health threat, increased time spent with families, and decreased time away from home could either intensity relationship problems or draw families closer to each other. This study aimed to examine the perceived psychological distress and relationship quality among couples before and during MCO in Malaysia and factors predictive of participants' well-being. The Depression Anxiety Stress Scale-21, Perceived Relationship Quality Component Inventory, and the Warwick-Edinburgh Mental Well-being Scale were disseminated through the snowball sampling technique. The study found that the participants $(\mathrm{N}=124)$ perceived significantly higher levels of depression, anxiety, and stress during MCO compared to before MCO. However, no significant differences between the couples were found before and during MCO in relationship quality, except in the trust sub-scale. Trust in the couple was higher during MCO. Multiple regression results showed that depression and stress predicted participants' well-being negatively during MCO. In contrast, total relationship quality, sexual relationship quality, satisfaction and couple's trust predicted participants' well-being positively.
\end{abstract}

Keywords: Psychological distress, relationship quality, well-being, COVID-19 pandemic, movement control order.

\section{Introduction}

On 31 December 2019, the World Health Organisation (WHO) China Country Office was informed of cases of pneumonia unknown aetiology (unknown cause) detected in Wuhan City, Hubei Province of China, now known as Coronavirus disease (COVID-19). From 31st December 2019 through 3rd January 2020, a total of 44 case-patients with pneumonia of unknown aetiology were reported to WHO by the national authorities in China. As of 20 January 2020, 282 confirmed cases of 2019-nCoV have been reported from four countries including China (278 cases), Thailand ( 2 cases), Japan ( 1 case) and the Republic of Korea (1 case). As of 27 March 2020, the total global number of COVID-19 cases has surpassed 500,000 (WHO, 2020). As reported on 15 April 2020, there are 210 Countries and Territories around the world that have a total of 2,015,569 confirmed cases of the coronavirus COVID-19 and a death toll of 127,635 deaths (Worldometer, 15 April 2020).

On 16 March 2020, the Prime Minister of Malaysia announced the Movement Control Order (MCO) in Malaysia due to the COVID-19 pandemic, necessitating the closure of places of worship, work, and education. Families are encouraged to self-isolate and to "stay at home" to curb the spread of the virus (Jabatan Perdana Menteri, 2020). The COVID-19 pandemic MCO has been drastic changes at the individual and family level in the lives of families. Families are forced to adapt to various "new norms", such as working from home for working adults, and a transition to learning online for those who are going to school and university. Apart from that, parents experience the difficulty of having to work and take 
care of children at the same time from the same sphere of their homes (Spinelli et al., 2020). As the sequelae of the stress experienced in the family and spousal unit, studies have also indicated increased family conflicts and lower levels of quality in the relationship between spouses and family members (Luetke et al., 2020, Pieh et al., 2020). This is a serious issue as the couple or spousal unit of the family constitutes the core of the family's well-being and the children's physical and psychosocial development (Härkönen et al., 2017).

Pieh, O' Rourke, Budimir, and Probst (2020) reported that higher relationship quality contributed positively to mental well-being, and vice versa among the couple. The relationship aspects included satisfaction, trust, intimacy, commitment, and others. Low et al., (2020), found increased anxiety and depression and lower well-being among the general population during the COVID-19 pandemic. However, it is still unclear which aspects of relationship quality have been affected by this pandemic and whether the relationship quality affects the well-being of the couple.

\section{Objectives}

This study aimed to examine the perceived psychological distress and relationship quality among couples before and during MCO in Malaysia and factors that affect participants' well-being.

\section{Methods}

\subsection{Participants}

A total of 560 participants who were 18 years old and above, had married or cohabiting couples and citizens of Malaysia were involved in the current study. The sample was selected randomly using a convenience sampling method. A self-administered online survey questionnaire was distributed on WhatsApp, Telegram, Facebook, Email, etc. to the targeted couples. There were 246 (or 43.9\%) males and 314 females who participated. Their age ranged from 21 to 67 years old $($ mean $=40.38$, s.d $=11.43)$. In term of current relationship status, most of the respondents were marriage (92\%), there were $32(5.7 \%)$ adults in a committed relationship and living together, $12(2.1 \%)$ of them had engaged and living together with a partner. The average year of married of participants was 14.8 years $(\mathrm{s} . \mathrm{d}=10.71)$.

\subsection{Instruments}

The instrument used contained four parts: the demographic data consisted of age, gender, current relationship status, and duration of a relationship. Part 2, The Depression Anxiety Stress Scales (DASS-21) designed by Lovibond and Lovibond (1995). DASS consisted of 21 items, seven items for each subscale. The item response format was on a 4-point scale $(0=$ did not apply to me at all to 3 = applied to me very much or most of the time). The reliability for DASS-21 showed very good reliability in the current study. The Alpha Cronbach = .94 (data during MCO) and .92 (data before MCO) for depression scale, the Alpha Cronbach $=.93$ and .89 during and before MCO for anxiety scale and Alpha Cronbach $=.93$ (during MCO) and .89 (before MCO) for stress scale.

The Perceived Relationship Quality Component (PRQC) Inventory designed by Fletcher et al. (2000) was used to assess relationship quality. PRQC contained 18 items that measured six components - relationship satisfaction, commitment, intimacy, trust, passion, and love. Each component consisted of three items and rated on a 7 -point scale (where $1=$ not at all to $7=$ extremely). PRQC also consisted of one additional component - sex relationship quality measured by six items. The internal consistency of the total PRQC in the current study was Alpha Cronbach $=.97$ (data during MCO) and Alpha Cronbach $=.93$ (data before MCO).

Warwick-Edinburgh Mental Well-being Scale (WEMWBS), contained 14 items that measured positive aspects of mental health within two weeks. It covered both hedonic and eudaimonic aspects. The items were rated on a 5-point Likert scale ranging from $1=$ None of the time to $5=$ All of the time, and a global score is obtained adding all the items. Higher scores indicating higher levels of mental well-being. WEMWBS showed very good reliability for the current study with a Cronbach's Alpha = .96.

\subsection{Data analysis}

Statistical analysis was performed using Program IBM SPSS Statistic version 25.0. Descriptive statistics such as frequency and percentage were used to report demographic information of participants, Pair Samples t-test was used to analyse the difference in perceiving psychological distress and relationship quality during and before COVID-19 pandemic MCO among couples in Malaysia. The multiple regression analysis was conducted to determine the effect of relationship quality on participants' well-being during the COVID-19 pandemic. 


\section{Results}

\subsection{Psychological distress level before and during COVID-19 pandemic movement control order (MCO)}

Paired samples t-test was used to analyse perceive psychological distress and relationship quality among couples before and during MCO in Malaysia. The result revealed that the depression $(\mathrm{t}=6.20$, $\mathrm{p}<.05)$, anxiety $(\mathrm{t}=5.58, \mathrm{p}<.05)$, and stress $(\mathrm{t}=5.16, \mathrm{p}<.05)$ perceived by respondents different significantly before and during MCO in Malaysia due to the COVID-19 pandemic. We found that the couples perceived a significantly higher level of depression, anxiety, and stress during COVID-19 pandemic MCO as compared to before MCO (refer to Table 1).

Table 1. The Pair Samples t-test for the Psychological Distress among Couples Before and During COVID-19 Pandemic MCO In Malaysia.

\begin{tabular}{lccccc}
\hline Variables & $\mathrm{N}$ & Mean & Std. Deviation & $\mathrm{t}$ & Sig. \\
\hline Depression During MCO & 557 & 2.96 & 3.79 & 11.33 & .000 \\
Depression Before MCO & 557 & 1.73 & 2.93 & & \\
Anxiety During MCO & 557 & 3.34 & 3.75 & 11.50 & .000 \\
Anxiety Before MCO & 557 & 2.11 & 3.05 & & \\
Stress During MCO & 555 & 4.37 & 4.22 & 11.89 & .000 \\
Stress Before MCO & 555 & 2.95 & 3.44 & & \\
\hline
\end{tabular}

\subsection{Relationship quality before and during COVID-19 pandemic movement control order (MCO)}

We found that the couples reported significantly lower satisfaction with partner $(\mathrm{t}=-3.40$, $\mathrm{p}<.05)$, but more committed in relationship $(\mathrm{t}=3.23, \mathrm{p}<.05)$, passion $(\mathrm{t}=2.97, \mathrm{p}<.05)$ and love $(\mathrm{t}=3.01, \mathrm{p}<.05)$ in relationship during COVID-19 pandemic MCO as compared to before MCO (refer to Table 2).

Table 2. The Pair Samples t-test for the Relationship Quality among Couples Before and During MCO in Malaysia.

\begin{tabular}{lccccc}
\hline Variables & $\mathrm{N}$ & Mean & Std. Deviation & $\mathrm{t}$ & Sig. \\
\hline Relationship Quality During MCO & 558 & 110.50 & 15.97 & 1.44 & .150 \\
Relationship Quality Before MCO & 558 & 110.05 & 15.74 & & \\
Satisfaction During MCO & $\mathbf{5 6 0}$ & $\mathbf{1 8 . 1 1}$ & $\mathbf{3 . 3 8}$ & $\mathbf{- 3 . 4 0}$ & $\mathbf{. 0 0 1}$ \\
Satisfaction Before MCO & $\mathbf{5 6 0}$ & $\mathbf{1 8 . 4 2}$ & $\mathbf{3 . 0 9}$ & & \\
Commitment During MCO & $\mathbf{5 6 0}$ & $\mathbf{1 8 . 8 9}$ & $\mathbf{2 . 8 9}$ & $\mathbf{3 . 2 3}$ & $\mathbf{. 0 0 1}$ \\
Commitment Before MCO & $\mathbf{5 6 0}$ & $\mathbf{1 8 . 6 9}$ & $\mathbf{2 . 8 9}$ & & \\
Intimacy During MCO & 559 & 18.73 & 3.06 & 1.73 & .084 \\
Intimacy Before MCO & 559 & 18.61 & 2.99 & & \\
Passion During MCO & $\mathbf{5 5 9}$ & $\mathbf{1 8 . 6 9}$ & $\mathbf{2 . 8 9}$ & $\mathbf{2 . 9 7}$ & $\mathbf{. 0 0 3}$ \\
Passion Before MCO & $\mathbf{5 5 9}$ & $\mathbf{1 8 . 5 2}$ & $\mathbf{2 . 9 0}$ & & \\
Trust During MCO & 560 & 17.03 & 3.68 & 1.37 & \\
Trust Before MCO & 560 & 16.91 & 3.53 & & \\
Love During MCO & $\mathbf{5 5 9}$ & $\mathbf{1 9 . 0 9}$ & $\mathbf{2 . 7 3}$ & $\mathbf{3 . 0 1}$ & $\mathbf{. 0 0 3}$ \\
Love Before MCO & $\mathbf{5 5 9}$ & $\mathbf{1 8 . 9 4}$ & $\mathbf{2 . 7 9}$ & & \\
Sex Quality During MCO & 559 & 37.01 & 5.49 & 1.15 & .253 \\
Sex Quality Before MCO & 559 & 36.87 & 5.42 & & \\
\hline
\end{tabular}

\subsection{The effect of relationship quality on well-being among couples during COVID-19 pandemic MCO}

The Multiple Regression analysis with the model 'Enter' was used to analyse the effect of relationship quality on well-being among the couples during MCO. The model that consisted of the six subscales of relationship quality significantly explained a total of $12.3 \%$ variance in well-being among the couples $\left(\mathrm{F}_{(6,553)}=11.44, \mathrm{p}<.05\right)$. The result further reported that the subscale of satisfaction with the relationship (beta $=.21$ ), intimacy $($ beta $=.20$ ) and passion in a relationship (beta $=.11$ ) predicted couples' well-being significantly and positively during COVID-19 pandemic MCO, which explained that the couples who satisfy with the relationship, intimacy and passion in a relationship with their partner tended to have better well-being during MCO, or in reverse. Besides, the model that consists only sex relationship quality, explained a total of $7.23 \%$ variance in well-being $\left(F_{(1,554)}=42.64, p<.05\right)$ and this subscale also predicted the respondents' well-being positively (Beta $=.27$ ) which explained that the respondents who have a quality sex relationship reported higher well-being, or in reverse (refer to Table 4). 
Table 4. Multiple Regression Analysis on The Effect of Relationship Quality on Well-Being among Couples During MCO In Malaysia.

\begin{tabular}{|c|c|c|c|c|}
\hline Predictor & & Beta & $\mathrm{t}$ & Sig. $t$ \\
\hline Satisfaction & & .21 & 3.02 & .003 \\
\hline Commitment & & -.15 & -1.76 & .080 \\
\hline Intimacy & & .20 & 2.14 & .033 \\
\hline Trust & & .06 & 0.83 & .405 \\
\hline Passion & & .11 & 2.05 & .040 \\
\hline Love & & -.09 & -1.29 & .199 \\
\hline $\mathrm{R}^{2}$ & .111 & & & \\
\hline $\mathrm{F}$ & 11.44 & & & \\
\hline Sig. F & .000 & & & \\
\hline
\end{tabular}

\section{Discussion and conclusions}

In this study, we found that the couples who reported a higher level of depression, anxiety, and stress during COVID-19 Pandemic MCO in Malaysia as compared to before MCO, and this contributed to decreasing their well-being. This finding was consistent with Xiong et al. (2020) findings that indicated a high level of depression, anxiety and stress in the general population in China, Spain, Italy, Iran, the US, Turkey, Nepal, and Denmark during the COVID-19 pandemic. A systematic review by Krishnamoorthy and colleagues (2020) revealed that more than half of the general population were adversely affected psychologically during the COVID-19 pandemic (Krishnamoorthy, Nagarajan, Saya, \& Menon, 2020). Günther-Bel and colleagues (2020) found that couples suffered from higher levels of psychological distress during the COVID-19 pandemic. They found that couples especially those with children reported higher levels of psychological distress during the lockdown in Spain, thus contributing to lower levels of well-being.

We also found sexual relationship quality, satisfaction, intimacy, and passion in relationship predicted participants' well-being positively during MCO. In terms of marital satisfaction, it is not surprising that these variables predict well-being positively during times of crisis, as has been found by many studies (e.g., Kayser et al., 2018). In terms of sexuality, it is interesting that couples in South-east Asian countries reported a significant increase in the frequency of sex compared to before lockdown (Arafat et al., 2020). However, the quality of sexuality may decrease due to the lack of privacy and stress experienced during lockdown (Panzeri, Ferrucci, Cozza, \& Fontanesi, 2020). Therefore, this aspect of the relationship needs to be safeguarded as the potential effects of guilt and stress from impaired sexuality could increase psychological distress during the pandemic (Banerjee \& Rao, 2020). The finding also revealed that the participant reported lower satisfaction with a partner, but higher commitment in relationship, passion and love in a relationship during MCO than before MCO.

In conclusion, Malaysian couples are facing increased psychological distress during the COVID-19 pandemic MCO. In terms of relationship quality, couples demonstrated lower satisfaction toward their spouses however, they showed higher commitment, passion and love in their relationship with their partner and these variables were significant predictors of their well-being. This study provides information and references to the healthcare professionals in developing COVID-19 psychological interventions which may help to cope with possible mental health problems. This study also increases couple awareness in a quality relationship and how it may influence their well-being. One of the limitations of this study was we employed an online survey, in which we were only able to reach the population segment that has access to the internet. For future studies, we suggested a longitudinal study design to track the changes in the participants' psychological distress, relationship quality and well-being concerning the development of the COVID-19 pandemic.

\section{References}

Arafat, S. Y., Mohamed, A. A., Kar, S. K., Sharma, P., \& Kabir, R. (2020). Does COVID-19 pandemic affect sexual behaviour? A cross-sectional, cross-national online survey. Psychiatry Research.

Banerjee, D., \& Rao, T. S. (2020). Sexuality, sexual wellbeing, and intimacy during COVID-19 pandemic: An advocacy perspective. Indian Journal of Psychiatry, 62(4), 418.

Fletcher, G. J., Simpson, J. A., \& Thomas, G. (2000). The measurement of perceived relationship quality components: A confirmatory factor analytic approach. Personality and Social Psychology Bulletin, 26(3), 340-354. 
Günther-Bel, C., Vilaregut, A., Carratala, E., Torras-Garat, S., \& Pérez-Testor, C. (2020). A Mixed-method Study of Individual, Couple, and Parental Functioning During the State-regulated COVID-19 Lockdown in Spain. Family Process, 59(3), 1060-1079.

Jabatan Perdana Menteri. (17 March 2020). Soalan Lazim (FAQ's) Mengenai Perintah Kawalan Pergerakan (Movement Control Order) - Dikemaskini. Retrieved April 9, 2020 from https://www.pmo.gov.my/2020/03/soalan-lazim-faqs-mengenai-perintah-kawalan-pergerakanmovement-control-order/

Kayser, K., Acquati, C., Reese, J. B., Mark, K., Wittmann, D., \& Karam, E. (2018). A systematic review of dyadic studies examining relationship quality in couples facing colorectal cancer together. Psycho-oncology, 27(1), 13-21.

Krishnamoorthy, Y., Nagarajan, R., Saya, G. K., \& Menon, V. (2020). Prevalence of psychological morbidities among general population, healthcare workers and COVID-19 patients amidst the COVID-19 pandemic: A systematic review and meta-analysis. Psychiatry Research, 293, 113382.

Lovibond, P. F., \& Lovibond, S. H. (1995). The structure of negative emotional states: Comparison of the Depression Anxiety Stress Scales (DASS) with the Beck Depression and Anxiety Inventories. Behaviour Research and Therapy, 33(3), 335-343.

Panzeri, M., Ferrucci, R., Cozza, A., \& Fontanesi, L. (2020). Changes in sexuality and quality of couple relationship during the Covid-19 lockdown. Frontiers in Psychology, 11, 565823.

Pieh, C., O' Rourke, T., Budimir, S., \& Probst, T. (2020). Relationship quality and mental health during COVID-19 lockdown. Plos One, 15(9), e0238906.

Sohrabi, C., Alsafi, Z., O’Neill, N., Khan, M., Kerwan, A., Al-Jabir, A., ... \& Agha, R. (2020). World Health Organization declares global emergency: A review of the 2019 novel coronavirus (COVID-19). International Journal of Surgery, 76, 71-76.

Stanley, S. M., \& Markman, H. J. (2020). Helping couples in the shadow of COVID-19. Family Process, 59(3), 937-955.

Tennant, R., Fishwick, R., Platt, S., Joseph, S., \& Stewart-Brown, S. (2006). Monitoring positive mental health in Scotland: Validating the Affectometer 2 scale and developing the Warwick-Edinburg Mental Well-being Scale for the UK. Glasgow: NHS Health Scotland.

Wu, Z., \& McGoogan, J. M. (2020). Characteristics of and important lessons from the coronavirus disease 2019 (COVID-19) outbreak in China: Summary of a report of 72314 cases from the Chinese Center for Disease Control and Prevention. JAMA, 323(13), 1239-1242.

Xiong, J., Lipsitz, O., Nasri, F., Lui, L. M., Gill, H., Phan, L., ... \& McIntyre, R. S. (2020). Impact of COVID-19 pandemic on mental health in the general population: A systematic review. Journal of Affective Disorders, 277, 55-64. 